\title{
Sleep disturbances following recovery from COVID-19: a comparative cross-sectional study in Egypt
}

Mohamed Abdelghani, ${ }^{1}$ Maha Alsadik, ${ }^{2}$ Ahmed Abdelmoaty, ${ }^{3}$ Samar Atwa, ${ }^{1}$ Amira Said ${ }^{4}$ and Mervat Hassan ${ }^{1}$

${ }^{1}$ Department of Psychiatry, College of Medicine, Zagazig University, Zagazig, Egypt. ${ }^{2}$ Department of Chest Diseases, College of Medicine, Zagazig University, Zagazig, Egypt. ${ }^{3}$ Department of Tropical Medicine, College of Medicine, Zagazig University, Zagazig, Egypt. ${ }^{4}$ Department of Anaesthesia and Surgical Intensive Care, College of Medicine, Zagazig University, Zagazig, Egypt. (Correspondence to: Mohamed Abdelghani: abdelghanim@alumni.vcu. edu).

\begin{abstract}
Background: Sequelae from COVID-19 are increasingly being reported, but sleep disturbances after recovery from the disease have had little attention.

Aims: This study aimed to identify and compare sleep disturbances and associated correlates among adults who have recovered from COVID-19 with those who have never been infected with the disease.

Methods: The sample included 85 adults who have recovered from COVID-19 and 85 adults who have never been infected (matched on age, sex, education and socioeconomic level). Individuals were recruited from Zagazig University Hospitals, Egypt from 1 September to 29 November 2020. Participants were interviewed using a sociodemographic and clinical checklist, the Pittsburgh Sleep Quality Index and the Hospital Anxiety Depression Scale.

Results: Most (77\%) of the recovered cases had experienced sleep disturbances, compared with $46 \%$ of controls. Individuals who had recovered from COVID-19 were more likely to have poor subjective sleep quality (odds ratio (OR) 1.5, 95\% confidence interval (CI): 1.1-2.1), prolonged sleep latency (OR 1.8, 95\% CI: 1.3-2.6), shorter sleep duration (OR 1.6, 95\% CI: 1.1-2.2), reduced sleep efficiency (OR 3.8, 95\% CI: 2.0-7.1), frequent daytime dysfunction (OR 1.9, 95\% CI: 1.2-3.1) and poor global Pittsburgh Sleep Quality Index score (OR 3.0, 95\% CI: 1.5-6.0). Depressive $(P=0.002)$ and anxiety $(P=0.003)$ symptoms were associated with a poor global Pittsburgh Sleep Quality Index score among recovered female participants $(P=0,034)$ who had low-to-medium education level $(P=0.004)$.
\end{abstract}

Conclusions: Further studies (e.g. population-based longitudinal studies) are needed on sleep disturbances as a potential sequelae of COVID-19, because it can impair mental and physical well-being.

Keywords: COVID-19, sleep disorders, depression, anxiety, Egypt

Citation: Abdelghani M; Alsadik M; Abdelmoaty A; Atwa S; Said A; Hassan M. Sleep disturbances following recovery from COVID-19: a comparative crosssectional study in Egypt. East Mediterr Health J. 2022; 28(1):14-22. https://doi.org/10.26719/emhj.22.006

Received: 23/01/21; accepted: 15/06/21

Copyright $\odot$ World Health Organization (WHO) 2022. Open Access. Some rights reserved. This work is available under the CC BY-NC-SA 3.0 IGO license (https://creativecommons.org/licenses/by-nc-sa/3.0/igo).

\section{Introduction}

COVID-19 was first detected in Wuhan, China, in late 2019 and it spread rapidly across the globe. It is a respiratory illness caused by a newly discovered severe acute respiratory syndrome coronavirus-2 (SARS-CoV-2) $(1,2)$. In March 2020, the World Health Organization (WHO) declared it a global pandemic (3). The causative virus was thought to be primarily transmitted through respiratory droplets and close contact. However, there no conclusive evidence yet about the nature and course of this new, rapidly transmissible and potentially fatal virus (4).

With the increasing COVID-19-related morbidity and mortality, many people are experiencing COVID19-related fears, depression and burnout symptoms and increased levels of physical and psychological distress $(5,6)$. The pandemic itself, the social restrictions and lockdown regulations imposed to halt the spread of the virus, and the resulting financial problems caused to people are affecting mental health and well-being negatively (7). Based on previous outbreaks such as the severe acute respiratory syndrome (SARS) and Middle East respiratory syndrome (MERS), recent studies have claimed that COVID-19 patients may suffer from neuropsychiatric sequelae (8), such as depression, anxiety and sleep disturbances (9). Even after stabilization of a good number of people have reported post-recovery sequalae. According to a recent Italian study, several patients who survived the COVID-19 experienced at least one psychiatric disorder, such as anxiety, depressive disorders or post-traumatic stress disorder, which was diagnosed during follow-up one month after hospital treatment or home isolation (10).

Sleep is essential for a person's physical and mental health (11,12). Interrupting the normal sleep cycle can result in prolonged wakening or insomnia, shortened sleep cycle, nightmares and daytime somnolence and fatigue (11). Potential factors associated with sleep disturbances include severe stressful conditions, emotional disturbances (e.g. depression and anxiety), trauma (either physical or psychological) and/or overuse of technology, especially social media $(13,14)$. 
Despite the high prevalence of sleep disturbances and other psychiatric symptoms among COVID-19 patients (prevalence 34\%) (9) to date, limited data exist on the psychopathological effects of COVID-19 on people in the early post-illness remission period. Thus, this study aimed to investigate the prevalence and potential risk factors for sleep disturbances in people who had recovered from COVID-19 and their control counterparts.

\section{Methods}

\section{Study design and participants}

This was a comparative cross-sectional study conducted from 1 September to 29 November 2020. A total of 85 adults were selected consecutively who had recovered from COVID-19 and were discharged according to the WHO discharge criteria (15) adopted by the Zagazig University committee for COVID-19 isolation hospitals.They had been diagnosed with COVID-19 based on the presence of viral nucleic acid in the nasopharyngeal swab and had either been hospitalized or had isolated at home. An equal number of volunteers, who had never been found positive for SARS-CoV-2, were included as a control group. They were first-degree relatives of participants who had recovered from COVID-19 and they were matched on age, sex, education and socioeconomic level. First-degree relatives were chosen to differentiate between the shared genetic, environmental and potential COVID-19-related effects on their mental health status. None of the investigators who interviewed the participants for this study had been involved in the treatment of the participants All recovered COVID-19 participants were interviewed in outpatient clinics at least one month after completing their home isolation or being discharged from hospital.

The sample size was calculated using Epi Info 6.0, assuming a prevalence of psychological symptoms of $41 \%$ and $21 \%$, respectively (16), in those who had COVID-19 and the general population at $80 \%$ power of the study and $95 \%$ confidence level. This gave a sample size of 170 participants (85 COVID-19 cases and 85 controls) (17). The following people were excluded: those younger than 18 years or older than 60 years, those with major physical (e.g. heart failure, renal failure and hepatic failure) or mental illness (e.g. acute psychosis, dementia and mental retardation), illiterate people and those who declined to participate.

\section{Data collection}

The participants were requested to complete a semi-structured checklist designed to collect relevant sociodemographic and clinical data. The checklist included questions about age, sex, marital status, residence, level of education, occupation, and history of psychiatric illness and/or medical illness. Low-to-medium educational level was defined as attaining a basic or secondary education, while high educational level included those with university or postgraduate education.

\section{Questionnaires}

We used the Structured Clinical Interview for DSM5 Axis I Disorders (SCID-5) (18) - a semi-structured tool - to help exclude the presence of current major acute or chronic primary mental illnesses (e.g. psychosis, mental retardation or dementia) in our participants, as these could affect the results if present. Several studies have established the validity and reliability of this tool $(19,20)$. Thus, all participants enrolled in our study for further psychometric assessment had no history of major psychiatric illnesses.

The Hospital Anxiety and Depression Scale is a self-report tool used to screen for symptoms of anxiety and depression. It consists of seven questions each on depressive and anxiety symptoms, with a four-point Likert scale scoring rage 0 to 3 . The total score of each subscale ranged from 0 to 21 (21). Participants were considered to have comorbid anxiety or depressive symptoms if their scores on this scale were $\geq 11$ points. We used a validated Arabic version of this scale (22).

The Pittsburgh Sleep Quality Index (PSQI) questionnaire is a self-report questionnaire to assess sleep quality in the past month. It consists of 19 items assessing seven domains of sleep quality - subjective sleep quality, sleep latency, sleep duration, sleep efficiency, sleep disturbance, use of sleeping medication and daytime dysfunction. Each domain is scored equally on a $0-3$ scale. Scores for all seven domains are summed to produce a global Pittsburgh Sleep Quality Index score, ranging from o to 21. Poor global sleep quality was defined as a global Pittsburgh Sleep Quality Index score of $\geq 5$, and the higher the score, the worse the sleep quality (23). We used a validated Arabic version of this scale (24).

\section{Ethical considerations}

The protocol of this study was approved by the institutional review board of Zagazig University (no. 6304-2-92020), and all study procedures were conducted within the ethical guidelines of the Declaration of Helsinki and its later amendments. Written informed consent was obtained from all the participants after explaining the study objectives and confirming confidentiality.

\section{Statistical analysis}

We used SPSS, version 16 to analyse the data. The chisquare test was used to compare proportions of categorical variables, while continuous variables were analysed using the independent sample t-test to compare the means of two groups. The Mann-Whitney-U test was used for data that were not normally distributed. Conditional logistic regression analysis was used to obtain odds ratios (OR) and 95\% confidence intervals (CI) of sleep disturbances among COVID-19 and control participants after adjusting for associated anxiety and depressive symptoms. Associations were considered statistically significant at $P<0.05$. 


\section{Results}

\section{Characteristics}

A total of 98 recovered COVID-19 patients were approached, of whom $13(13 \%)$ either declined to participate or did not complete the questionnaire: those who failed to complete the questionnaire and their control family members were excluded from the analysis. Of all participants who had CIVID-19, 45 (53\%) had been discharged from hospital as they had moderate-to-severe symptoms and $40(47 \%)$ had self-isolated as they reported mild symptoms of COVID-19 infection.

The mean age of participants who had recovered from COVID-19 was 35.95 (standard deviation 9.4) years, and most of them were women $(81 \%)$, married $(88 \%)$, of low-to-medium educational level $(62 \%)$ and were skilled workers (91\%). The prevalence of anxiety and depressive symptoms in recovered participants was 25\% (21/85) and $29 \%(25 / 85)$, respectively, which was higher than that of the controls (15\% (13/85) and 8\% (7/85), respectively). No statistically significant differences in sociodemographic variables were found between the two groups, or in their history of mental or medical illness. However, recovered participants had significantly higher mean anxiety and depressive scores than their control counterparts; $P=0.001$ and $P=0.003$, respectively (Table 1 ).

\section{Sleep disturbances in recovered participants}

The prevalence of sleep disturbances among recovered COVID-19 cases and control participants was 76\% (65/85) and $46 \%(39 / 85)$, respectively. Compared to the control group, the recovered participants had significantly higher levels of sleep disturbances in all domains assessed by the Pittsburgh Sleep Quality Index questionnaire except the use of medications, namely: sleep quality $(P<0.001)$, latency $(P<0.001)$, duration $(P=0.003)$, efficiency $(P<0.001)$, disturbances $(P=0.002)$, daytime dysfunction $(P<0.001)$ and global PSQI score $(P<0.001)$ (Table 2). Even after adjusting for associated anxiety and depressive symptoms, the recovered participants had higher odds of impairment in sleep quality (OR 1.48, 95\% CI: 1.05-2.10; $P=0.026)$, latency (OR 1.82, 95\% CI: 1.29-2.57; $P=0.001)$, duration (OR 1.57, 95\% CI: 1.11-2.22; $P=0.011$ ), efficiency (OR 3.77, 95\% CI: 2.00-7.12; $P<0.001$ ), daytime functioning (OR 1.94, 95\% CI: 1.21-3.11; $P=0.006)$ and poor global PSQI score (OR 3.0, 95\% CI: 1.50-6.01; $P=0.002$ ) (Table 3).

\begin{tabular}{|c|c|c|c|c|}
\hline Variable & Cases $(n=85)$ & Controls $(n=85)$ & Statistical test & P-value \\
\hline Age, mean (SD) & $35.95(9.40)$ & $33.68(9.37)$ & $t=1.58$ & 0.117 \\
\hline Sex, no. (\%) & & & $\chi^{2}=1.63$ & 0.202 \\
\hline Female & $69(81.2)$ & $62(72.9)$ & & \\
\hline Male & $16(18.8)$ & $23(27.1)$ & & \\
\hline Marital status, no. (\%) & & & $\chi^{2}=3.37$ & 0.066 \\
\hline Married & $75(88)$ & $66(78)$ & & \\
\hline Not married & $10(12)$ & $19(22)$ & & \\
\hline Residence, no. (\%) & & & $\chi^{2}=1.976$ & 0.160 \\
\hline Rural & $55(65)$ & $46(54)$ & & \\
\hline Urban & $30(35)$ & $39(46)$ & & \\
\hline Level of education, no. (\%) & & & $\chi^{2}=0.61$ & 0.435 \\
\hline Low-to-medium & $53(62)$ & $48(57)$ & & \\
\hline High & $32(38)$ & $37(43)$ & & \\
\hline Occupation, no. (\%) & & & $\chi^{2}=2.65$ & 0.266 \\
\hline Skilled & 77 (91) & $70(82)$ & & \\
\hline Government employee & $7(8)$ & $12(14)$ & & \\
\hline Unemployed & $1(1)$ & $3(2)$ & & \\
\hline History of psychiatric illnesses, no. (\%) & & & $\chi^{2}=0.083$ & 0.773 \\
\hline Yes & $7(8)$ & $6(7)$ & & \\
\hline No & $78(92)$ & 79 (93) & & \\
\hline History of medical illnesses, no. (\%) & & & $\chi^{2}=2.590$ & 0.108 \\
\hline Yes & $19(22)$ & $11(13)$ & & \\
\hline No & $66(78)$ & $74(87)$ & & \\
\hline \multicolumn{5}{|l|}{ HADS score, mean (SD) } \\
\hline Depression & $8.24(4.21)$ & $6.62(3.85)$ & MWU $=-2.95$ & 0.003 \\
\hline Anxiety & $8.15(4.17)$ & $6.13(3.37)$ & $M W U=-3.33$ & 0.001 \\
\hline
\end{tabular}




\begin{tabular}{|c|c|c|c|c|}
\hline Variable & $\begin{array}{c}\text { Cases }(n=85) \\
\text { Mean (SD) }\end{array}$ & $\begin{array}{c}\text { Controls }(n=85) \\
\text { Mean (SD }\end{array}$ & Mann-Whitney U test & P-value ${ }^{\mathrm{a}}$ \\
\hline Sleep quality & $1.71(0.98)$ & $1.20(0.97)$ & -3.49 & $<0.001$ \\
\hline Sleep latency & $1.82(0.93)$ & $1.16(1.00)$ & -4.25 & $<0.001$ \\
\hline Sleep duration & $1.14(1.05)$ & $0.68(0.88)$ & -2.97 & 0.003 \\
\hline Sleep efficiency & $0.72(0.88)$ & $0.18(0.41)$ & -4.69 & $<0.001$ \\
\hline Sleep disturbances & $1.59(0.66)$ & $1.34(0.68)$ & -2.30 & 0.002 \\
\hline Use of medications & $0.35(0.88)$ & $0.16(0.60)$ & -1.65 & 0.099 \\
\hline Daytime dysfunction & $1.13(0.80)$ & $0.71(0.65)$ & -3.51 & $<0.001$ \\
\hline Global PSQI & No. $(\%)$ & No. $(\%)$ & \multirow{3}{*}{$\chi^{2}=16.74$} & \\
\hline Good $(<5)$ & $20(23.5)$ & $46(54.1)$ & & \multirow{2}{*}{$<0.001$} \\
\hline Poor $(\geq 5)$ & $65(76.5)$ & 39 (45.9) & & \\
\hline
\end{tabular}

COVID-19: coronavirus disease 2019; SD: standard deviation; PSQI: Pittsburgh Sleep Quality Index

${ }^{a}$ Significant at $P<0.05$.

Among recovered participants with poor scores on the global Pittsburgh Sleep Quality Index, 29\% (25/85) and $36 \%(31 / 85)$, had associated anxiety and depressive symptoms, respectively, which was higher than that of recovered participants with good global Pittsburgh Sleep Quality Index scores $(10 \%(9 / 85 ; 11 \%)$ and $5 \%(4 / 85$; $5 \%$ ), respectively). There were significant associations between poor global Pittsburgh Sleep Quality Index scores and being female $(P=0.034)$, low-to-medium level of education $(P=0.004)$ and associated depressive $(P=0.002)$ and anxiety symptoms $(P=0.003)$ (Table 4$).$

\section{Discussion}

The main finding of this study is that about $77 \%$ of people who had recovered from COVID-19 experienced sleep disturbances (compared to only $46 \%$ of control participants). Moreover, the recovered participants were more likely to have poor subjective sleep quality, prolonged sleep latency, shorter sleep duration, reduced sleep efficiency, more frequent daytime dysfunction, and poor global Pittsburgh Sleep Quality Index scores compared to the controls. These findings are supported by the results of previous studies on disease outbreaks, where psychiatric morbidities, including sleep disturbances, ranged from $10 \%$ to $35 \%$ in the post-remission period $(8,25)$. For example, a Nigerian study found that out of 117 partic- ipants, including survivors of Ebola virus disease and their families, $39(33 \%)$ reported sleep insufficiency attributed to epidemic-related fears (26). A meta-analysis of eight studies concluded that the prevalence of sleep disturbances in post-recovery COVID-19 patients in China, Turkey and Italy was $35 \%, 13 \%$ and $50 \%$, respectively (9). The sleep disturbances associated with the COVID-19 outbreak could be attributed to psychological stressors such as social restrictions, the psychological impact of a new virus with potentially severe morbidity and mortality, apprehensions about infection or infecting others, and illness stigma.

However, the higher propensity for psychological disturbances, including sleep disturbances, among people who have recovered from COVID-19 than people who have not had COVID-19 but who share the same environmental stressors raises concerns about the potential neuroimmunological effects of the COVID-19 virus itself. It has been claimed that the immune reaction induces local and systemic cytokine infiltrations and, similar to SARS and MERS patients, COVID-19 patients showed T-helper-1 cell overstimulation with overproduction of interferon- $\gamma$, interleukin (IL)-1 $\beta$, IL-6, CXCL10 and CCL2 $(27,28)$. However, unlike in SARS and MERS, activation of T-helper-2 cells with overproduction of cytokines (such as IL-4 and IL-10) has been detected in COVID-19 patients (29). Evidence suggests that

\begin{tabular}{lccccc}
\hline Table 3 Association of COVID-19 with sleep problems: conditional logistic regression analysis & \\
Variable & $\boldsymbol{\beta}$ & SE & Wald & P-value & aOR $^{\mathbf{a}}(\mathbf{9 5} \% \mathbf{C I})$ \\
Sleep quality & 0.40 & 0.18 & 4.99 & 0.026 & $1.48(1.05-2.10)$ \\
Sleep latency & 0.60 & 0.18 & 11.82 & 0.001 & $1.82(1.29-2.57)$ \\
Sleep duration & 0.45 & 0.18 & 6.48 & 0.011 & $1.57(1.11-2.22)$ \\
Sleep efficiency & 1.33 & 0.32 & 16.78 & $<0.001$ & $3.77(2.00-7.12)$ \\
Sleep disturbances & 0.30 & 0.25 & 1.44 & 0.23 & $1.36(0.82-2.23)$ \\
Daytime dysfunction & 0.66 & 0.24 & 7.58 & 0.006 & $1.94(1.21-3.11)$ \\
Poor global PSQI & 1.10 & 0.36 & 9.56 & 0.002 & $3.00(1.50-6.01)$ \\
\hline
\end{tabular}

COVID-19: coronavirus disease 2019; $\beta$ : regression coefficient; SE: standard error; aOR: adjusted odds ratio; CI confidence interval; PSQI: Pittsburgh Sleep Quality Index.

"aORs adjusted for associated depression and anxiety symptoms. 


\begin{tabular}{|c|c|c|c|c|}
\hline \multirow[t]{2}{*}{ Variable } & \multicolumn{2}{|c|}{ Global PSQI score } & \multirow[t]{2}{*}{ Statistical test } & \multirow[t]{2}{*}{ P-value ${ }^{a}$} \\
\hline & Good $(<5)(n=20)$ & Poor $(\geq 5)(n=65)$ & & \\
\hline Age, mean (SD) & $33.05(9.67)$ & $36.85(9.21)$ & $t=-1.59$ & 0.115 \\
\hline Sex, no. (\%) & & & $\chi^{2}=4.48$ & 0.034 \\
\hline Female & $13(65)$ & $56(86)$ & & \\
\hline Male & 7 (35) & $9(14)$ & & \\
\hline Marital status, no. (\%) & & & $\chi^{2}=1.71$ & 0.191 \\
\hline Married & $16(80)$ & $59(91)$ & & \\
\hline Not married & $4(20)$ & $6(9)$ & & \\
\hline \multicolumn{5}{|l|}{ Residence, no. (\%) } \\
\hline Rural & $14(70)$ & $41(63)$ & $\chi^{2}=0.32$ & 0.388 \\
\hline Urban & $6(30)$ & $24(37)$ & & \\
\hline \multicolumn{5}{|l|}{ Level of education, no. (\%) } \\
\hline Low-to-medium & $7(35)$ & $46(71)$ & $\chi^{2}=8.34$ & 0.004 \\
\hline High & $13(65)$ & $19(29)$ & & \\
\hline \multicolumn{5}{|l|}{ Occupation, no. (\%) } \\
\hline Skilled & $19(95)$ & $58(89)$ & $\chi^{2}=0.70$ & 0.706 \\
\hline Employee & $1(5)$ & $6(9)$ & & \\
\hline Unemployed & $0(0)$ & $1(1)$ & & \\
\hline \multicolumn{5}{|l|}{ History of psychiatric illnesses, no. (\%) } \\
\hline Yes & $3(15)$ & $4(6)$ & $\chi^{2}=1.58$ & 0.208 \\
\hline No & $17(85)$ & $61(94)$ & & \\
\hline \multicolumn{5}{|l|}{ History of medical illnesses, no. (\%) } \\
\hline Yes & $2(10)$ & $17(26)$ & $\chi^{2}=2.30$ & 0.129 \\
\hline No & $18(90)$ & $48(74)$ & & \\
\hline \multicolumn{5}{|l|}{ Severity of COVID-19 symptoms, no. (\%) } \\
\hline Mild & $11(55)$ & $29(45)$ & $\chi^{2}=0.66$ & 0.416 \\
\hline Moderate-to-severe & $9(45)$ & $36(55)$ & & \\
\hline \multicolumn{5}{|c|}{ Medications given during COVID-19 infection, no. (\%) } \\
\hline Antibiotics & $17(85)$ & $57(88)$ & $\chi^{2}=0.01$ & 0.925 \\
\hline Anticoagulants & $12(60)$ & $37(57)$ & $\chi^{2}=0.15$ & 0.700 \\
\hline Antimalarial & $9(45)$ & $28(43)$ & $\chi^{2}=0.06$ & 0.804 \\
\hline Antiparasitic (ivermectin) & $12(60)$ & $41(63)$ & $\chi^{2}=0.02$ & 0.894 \\
\hline Steroids & $8(40)$ & $37(57)$ & $\chi^{2}=1.68$ & 0.195 \\
\hline Home isolation in days, mean (SD) & $11.71(8.90)$ & $9.11(9.90)$ & $M W U=-0.92$ & 0.359 \\
\hline Hospital isolation in days, mean (SD) & $4.94(6.70)$ & $6.97(9.62)$ & $M W U=-0.59$ & 0.558 \\
\hline \multicolumn{5}{|l|}{ HADS score, mean (SD) } \\
\hline Depression & $6.05(4.12)$ & $8.83(4.33)$ & $\mathrm{MWU}=-3.08$ & 0.002 \\
\hline Anxiety & $5.95(2.69)$ & $8.70(4.45$ & $\mathrm{MWU}=-2.99$ & 0.003 \\
\hline
\end{tabular}

COVID-19: coronavirus disease 2019; SD: standard deviation; HADS: Hospital Anxiety and Depression Scale; MWU test: Mann-Whitney U test.

aSignificant at $\mathrm{P}<0.05$.

the activation of the immune system with release of pro-inflammatory cytokines was associated with the development of psychiatric symptoms (30). Many studies have found that coronaviruses could infect neuronal cells by binding to the angiotensin-convertase enzyme receptor 2 (ACE2) expressed by neuronal cells (31-33). The invasion of the coronavirus into the central nervous system, including the brainstem which is responsible for cardiorespiratory control, would result in respiratory insufficiency (32). With the prolonged respiratory dysregulation as a result of neurological injury, recovered patients may experience a worsening of their quality of sleep induced by breathing difficulties (34). Accordingly, the virus could also have a role in the emergence of sleep disorders in recovered COVID-19 patients through immune-neurological mechanisms.

Our study shows that female and having higher levels of depression and anxiety symptoms predicted poor scores on the global Pittsburgh Sleep Quality Index 
among recovered participants. A similar study found that females had an increased risk of developing insomnia (35). However, another study found that male COVID-19 patients were more likely to report sleep-related problems (36). These apparent differences regarding sex as a risk factor for sleep disturbances in COVID-19 patients could be attributed to variances in the studied subgroups, e.g. the general population, health care workers or COVID-19 patients.

Regarding the relationship between anxiety and depression and sleep disturbances, previous clinical studies had demonstrated the close association between emotional instability and sleep disturbances (37). In our study most of the participants were employed. It has been claimed that during the epidemic, elevated stress and anxiety levels associated with reduced social capital were linked with poor sleep quality and that people who had recovered from COVID-19 were more susceptible to experiencing adverse health outcomes $(38,39)$. This susceptibility could occur by affecting the emotional and intellectual capabilities, and even disturbing the other physiological functions such as cardiovascular, hormonal, immunological and metabolic functions (40). Furthermore, long-term recurrent episodes of insufficient sleep would lead to emotional symptoms and vice versa (41).

\section{Acknowledgement}

We thank all the participants who took part in this study.

Funding: None.

Competing interests: None declared.
Our study has some limitations. First, it was cross-sectional and thus we cannot establish a causal relationship between sleep disorders and related risk factors, including COVID-19. Second, the selection of participants from only one province, despite being one of the largest provinces in Egypt, and relatively small-sized sample limit the generalizability of our findings. Third, sleep disturbances, the main outcome, were assessed through a self-rating scale which would increase the possibility of recall bias. Therefore, more objective measures (e.g. polysomnography) would provide more accurate and reliable results.

\section{Conclusions}

Further attention needs to be given to sleep disturbances as one of the potential sequelae of COVID-19 because it can negatively affect mental and physical well-being. Tailored interventions targeting those with and most at risk of sleep disturbances following COVID-19 (e.g. women) could overcome/prevent such disorders. Population-based longitudinal studies are needed to investigate the various psychological and neurobiological mechanisms underlying sleep disturbances and to identify the other possible long-term sequelae of COVID-19 in Egypt.

\section{Troubles du sommeil après la guérison de la COVID-19 : étude transversale comparative en Égypte}

\section{Résumé}

Contexte : Les séquelles post-COVID-19 sont de plus en plus souvent signalées, mais les troubles du sommeil après la guérison de la maladie ont suscité peu d'attention.

Objectifs : La présente étude visait à identifier et à comparer les troubles du sommeil et les corrélats associés chez les adultes qui avaient guéri de la COVID-19 et chez ceux qui n'avaient pas contracté la maladie.

Méthodes: Les échantillons comprenaient 85 adultes guéris de la COVID-19 et 85 autres qui n'ont jamais été infectés de COVID-19 (appariés en fonction de l'âge, du sexe, du niveau d'éducation et du niveau socio-économique). Des personnes ont été recrutées dans les hôpitaux universitaires de Zagazig (Égypte) du $1^{\text {er }}$ septembre au 29 novembre 2020. Les participants ont été interrogés à l'aide d'une liste de contrôle socio-démographique et clinique, de l'index de qualité du sommeil de Pittsburgh et de l'échelle d'anxiété et de dépression de l'hôpital.

Résultats : La plupart (77\%) des cas de COVID-19 guéris avaient présenté des troubles du sommeil, contre $46 \%$ des témoins. Les personnes qui s'étaient rétablies de la COVID-19 étaient plus susceptibles d'avoir une mauvaise qualité subjective du sommeil (odds ratio (OR) 1,5, intervalle de confiance (IC) à $95 \%: 1,1-2,1$ ), une latence prolongée du sommeil (OR 1,8, IC à $95 \%$ : 1,3-2,6), une durée de sommeil plus courte (OR : 1,6, IC à $95 \%$ : 1,1-2,2), une efficacité courte du sommeil (OR 3,8, IC à $95 \%$ : 2,0-7,1), des dysfonctionnements fréquents pendant la journée (OR 1,9, IC à $95 \%: 1,2-3,1)$ et un score global médiocre de l'index de qualité du sommeil de Pittsburgh (OR 3,0, IC à 95\%: 1,5-6,0). Chez les participantes guéries $(p=0,034)$ qui avaient un niveau d'éducation compris entre faible et modéré $(p=0,004)$, les symptômes dépressifs $(p=0,002)$ et liés à l'anxiété $(p=0,003)$ étaient associés à un score global médiocre de l'index de qualité du sommeil de Pittsburgh.

Conclusion: D'autres études (par exemple, des études longitudinales en population) sont nécessaires sur les troubles du sommeil en tant que séquelles potentielles de la COVID-19 qui peuvent nuire au bien-être mental et physique. 


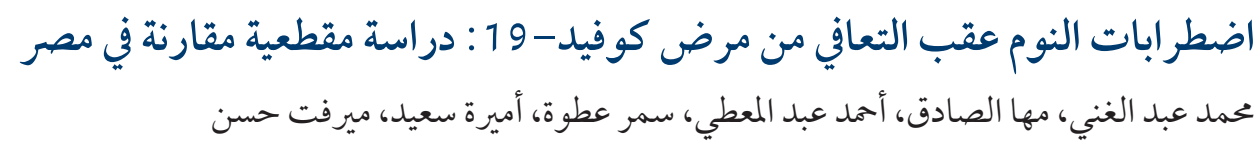

الخلفية: يتزايد الإبلاغ عن مضاعفات مرض فيروس كورونا 190 (كوفيد-19)، ولكن لم تحظَّ اضطرابات النوم التالية للإصابة بمرض كوفيد-19 بالاهتهام الكافي.

الأهداف: هدفت هذه الدراسة إلى تحديد اضطرابات النوم والمعاملات المرتبطة بها ومقارنتها بين البالغين الذين تعافوا من مرض كوفيد-19

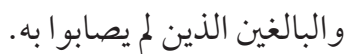

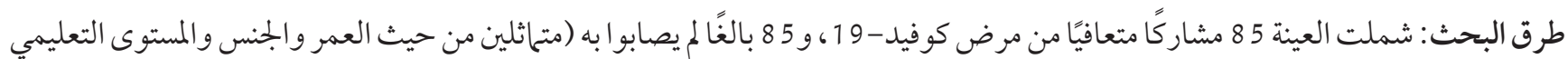

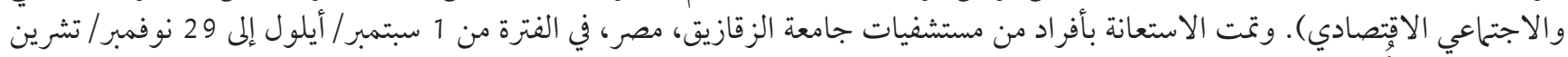

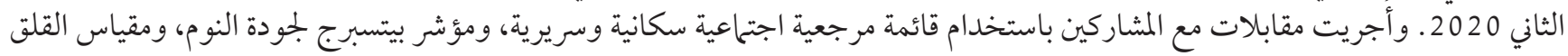
والاكتئاب في المستشفيات.

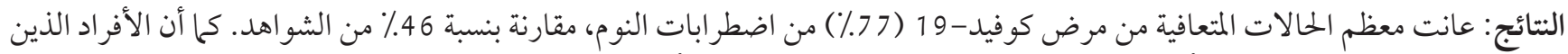

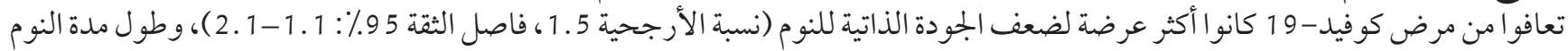

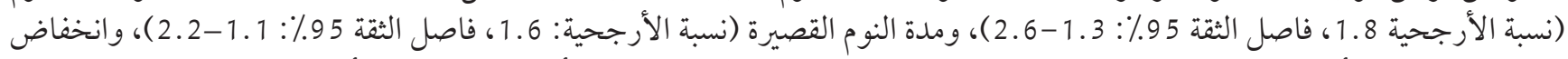

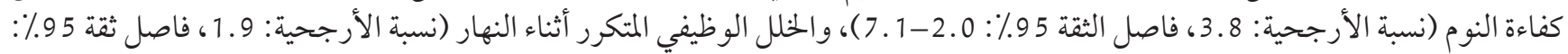

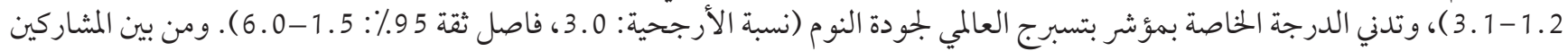

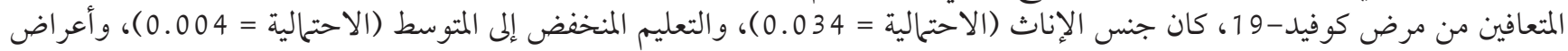

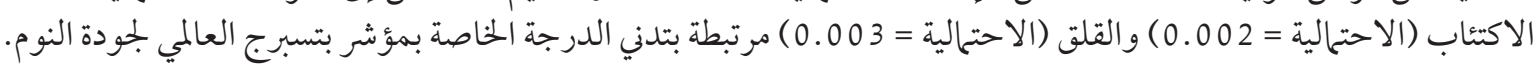

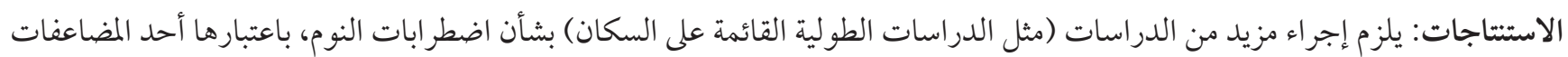

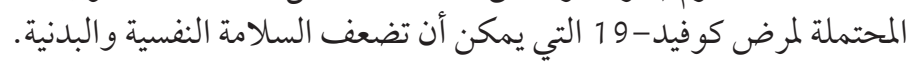

\section{References}

1. Qu G, Li X, Hu L, Jiang G. An imperative need for research on the role of environmental factors in transmission of novel coronavirus (COVID-19). Environ Sci Technol. 2020;54(7):3730-2. https://doi.org/10.1021/acs.est.oc01102

2. Sharma VK, Jinadatha C, Lichtfouse E. Environmental chemistry is most relevant to study coronavirus pandemics. Environ Chem Lett. 2020:1-4. https://doi.org/10.1007/s10311-020-01017-6

3. WHO Director-General's opening remarks at the media briefing on COVID-19 - 11 March 2020. Geneva: World Health Organization; 2020 (https://www.who.int/director-general/speeches/detail/who-director-general-s-opening-remarks-at-the-media-briefh ing-on-covid-19---11-march-2020, accessed 26 August 2021).

4. Liu S, Yang L, Zhang C, Xiang Y, Liu Z, Hu S, et al. Online mental health services in China during the COVID-19 outbreak. Lancet Psychiatry. 2020;7(4):e17-e18. https://doi.org/10.1016/S2215-0366(20)30077-8

5. Aljemaiah AI, Osman M, Alharbi S, Alshehri R, Aldggag EM, Aljoudi AT, et al. Fear at the time of the COVID-19 pandemic: validation of the Arabic version of the four-dimensional symptom questionnaire among Saudi-based respondents. BJPsych Open. 2021;7(1):e33. https://doi.org/10.1192/bjo.2020.166

6. Abdelghani M, El-Gohary HM, Fouad E, Hassan MS. Addressing the relationship between perceived fear of COVID-19 virus infection and emergence of burnout symptoms in a sample of Egyptian physicians during COVID-19 pandemic: a cross-sectional study. Middle East Curr Psychiatry. 2020;27(1):70. https://doi.org/10.1186/s43045-020-00079-0

7. Galea S, Merchant RM, Lurie N. The mental health consequences of COVID-19 and physical distancing: the need for prevention and early intervention. JAMA Intern Med. 2020;180(6):817-8. https://doi.org/10.1001/jamainternmed.2020.1562

8. Rogers JP, Chesney E, Oliver D, Pollak TA, McGuire P, Fusar-Poli P, et al. Psychiatric and neuropsychiatric presentations associated with severe coronavirus infections: a systematic review and meta-analysis with comparison to the COVID-19 pandemic. Lancet Psychiatry. 2020;7(7):611-27. https://doi.org/10.1016/s2215-0366(20)30203-0

9. Deng J, Zhou F, Hou W, Silver Z, Wong CY, Chang O, et al. The prevalence of depression, anxiety, and sleep disturbances in COVID-19 patients: a meta-analysis. Ann N Y Acad Sci. 2021;1486(1):90-111. https://doi.org/10.1111/nyas.14506

10. Mazza MG, De Lorenzo R, Conte C, Poletti S, Vai B, Bollettini I, et al. Anxiety and depression in COVID-19 survivors: role of inflammatory and clinical predictors. Brain Behav Immun. 2020;89:594-600. https://doi.org/10.1016/j.bbi.2020.07.037

11. Otsuka Y, Kaneita Y, Itani O, Nakagome S, Jike M, Ohida T. Relationship between stress coping and sleep disorders among the general Japanese population: a nationwide representative survey. Sleep Med. 2017;37:38-45. https://doi.org/10.1016/j. sleep.2017.06.007 
12. Institute of Medicine. Sleep disorders and sleep deprivation: an unmet public health problem. Washington, DC: The National Academies Press; 2006. https://doi.org/10.17226/11617

13. Seng EK, Cervoni C, Lawson JL, Oken T, Sheldon S, McKee MD, et al. The burden of sleep problems: a pilot observational study in an ethnically diverse urban primary care setting. J Prim Care Community Health. 2016;7(4):276-80. https://doi. org/10.1177/2150131916651068

14. Chattu VK, Manzar MD, Kumary S, Burman D, Spence DW, Pandi-Perumal SR. The global problem of insufficient sleep and its serious public health implications. Healthcare (Basel). 2018;7(1):1 https://doi.org/10.3390/healthcare7010001

15. Criteria for releasing COVID-19 patients from isolation: scientific brief, 17 June 2020. Geneva: World Health Organization; 2020 (https://apps.who.int/iris/handle/10665/332451, accessed 4 September 2021).

16. Zhang J, Lu H, Zeng H, Zhang S, Du Q, Jiang T, Du B. The differential psychological distress of populations affected by the COVID-19 pandemic. Brain Behav Immun. 2020;87:49-50. https://doi.org/10.1016/j.bbi.2020.04.031

17. Epi Info, version 6. Atlanta, GA: Centers for Disease Control and Prevention; 1994.

18. First MB. Structured clinical interview for the DSM (SCID). In: The encyclopedia of clinical psychology. Hoboken, NJ: John Wiley \& Sons, Inc.; 2014. https://doi.org/10.1002/9781118625392.

19. Osório FL, Loureiro SR, Hallak JEC, Machado-de-Sousa JP, Ushirohira JM, Baes CVW, et al. Clinical validity and intrarater and test-retest reliability of the Structured Clinical Interview for DSM-5-Clinician Version (SCID-5-CV). Psychiatry Clin Neurosci. 2019;73(12):754-60.

20. Shankman SA, Funkhouser CJ, Klein DN, Davila J, Lerner D, Hee D. Reliability and validity of severity dimensions of psychopathology assessed using the Structured Clinical Interview for DSM-5 (SCID). Int J Methods Psychiatr Res. 2018;27(1):e1590. https:// doi.org/10.1002/mpr.1590

21. Zigmond AS, Snaith RP. The hospital anxiety and depression scale. Acta Psychiatr Scand. Jun 1983;67(6):361-70. https://doi. org/10.1111/j.1600-0447.1983.tbo9716.x

22. El-Rufaie OE, Absood G. Validity study of the hospital anxiety and depression scale among a group of Saudi patients. Br J Psychiatry. 1987;151(5):687-8. https://doi.org/10.1192/bjp.151.5.687

23. Buysse DJ, Reynolds CF, 3rd, Monk TH, Berman SR, Kupfer DJ. The Pittsburgh Sleep Quality Index: a new instrument for psychiatric practice and research. Psychiatry Res. 1989;28(2):193-213. https://doi.org/10.1016/0165-1781(89)90047-4

24. Suleiman KH, Yates BC, Berger AM, Pozehl B, Meza J. Translating the Pittsburgh Sleep Quality Index into Arabic. West J Nurs Res. 2010;32(2):250-68. https://doi.org/10.1177/0193945909348230

25. Sheng B, Cheng SK, Lau KK, Li HL, Chan EL. The effects of disease severity, use of corticosteroids and social factors on neuropsychiatric complaints in severe acute respiratory syndrome (SARS) patients at acute and convalescent phases. Eur Psychiatry. 2005;20(3):236-42. https://doi.org/10.1016/j.eurpsy.2004.06.023

26. Mohammed A, Sheikh TL, Gidado S, Poggensee G, Nguku P, Olayinka A, et al. An evaluation of psychological distress and social support of survivors and contacts of Ebola virus disease infection and their relatives in Lagos, Nigeria: a cross sectional study, 2014. BMC Public Health. 2015;15:824. https://doi.org/10.1186/s12889-015-2167-6

27. Cameron MJ, Bermejo-Martin JF, Danesh A, Muller MP, Kelvin DJ. Human immunopathogenesis of severe acute respiratory syndrome (SARS). Virus Res. 2008;133(1):13-9. https://doi.org/10.1016/j.virusres.2007.02.014

28. Channappanavar R, Perlman S. Pathogenic human coronavirus infections: causes and consequences of cytokine storm and immunopathology. Semin Immunopathol. 2017;39(5):529-39. https://doi.org/10.1007/s00281-017-0629-x

29. Ye Q, Wang B, Mao J. The pathogenesis and treatment of the "cytokine storm" in COVID-19. J Infect. 2020;80(6):607-13. https:// doi.org/10.1016/j.jinf.2020.03.037

30. Arisi GM. Nervous and immune systems signals and connections: cytokines in hippocampus physiology and pathology. Epilepsy Behav. 2014;38:43-7. https://doi.org/10.1016/j.yebeh.2014.01.017

31. Bhayana R, Som A, Li MD, Carey DE, Anderson MA, Blake MA, et al. Abdominal imaging findings in COVID-19: preliminary observations. Radiology. 2020;297(1):E207-15. https://doi.org/10.1148/radiol.2020201908

32. Li YC, Bai WZ, Hashikawa T. The neuroinvasive potential of SARS-CoV2 may play a role in the respiratory failure of COVID-19 patients. J Med Virol. 2020;92(6):552-5. https://doi.org/10.1002/jmv.25728

33. To KF, Lo AW. Exploring the pathogenesis of severe acute respiratory syndrome (SARS): the tissue distribution of the coronavirus (SARS-CoV) and its putative receptor, angiotensin-converting enzyme 2 (ACE2). J Pathol. 2004;203(3):740-3. https://doi. org/10.1002/path.1597

34. Dyken ME, Yamada T, Berger HA. Transient obstructive sleep apnea and asystole in association with presumed viral encephalopathy. Neurology. 2003;60(10):1692-4. https://doi.org/10.1212/01.wnl.0000064166.82077.eb

35. Tasnim S, Rahman M, Pawar P, Chi X, Yu Q, Zou L, et al. Epidemiology of sleep disorders during COVID-19 pandemic: a systematic scoping review. medRxiv. 2020:2020.10.08.20209148. https://doi.org/10.1101/2020.10.08.20209148

36. Jahrami H, BaHammam AS, Bragazzi NL, Saif Z, Faris M, Vitiello MV. Sleep problems during COVID-19 pandemic by population: a systematic review and meta-analysis. J Clin Sleep Med. 2021;17(2):299-313. https://doi.org/10.5664/jcsm.8930 
37. Wu K, Wei X. Analysis of psychological and sleep status and exercise rehabilitation of front-line clinical staff in the fight against COVID-19 in China. Med Sci Monit Basic Res. 2020;26:e924085. https://doi.org/10.12659/msmbr.924085

38. Xiao H, Zhang Y, Kong D, Li S, Yang N. Social capital and sleep quality in individuals who self-isolated for 14 days during the coronavirus disease 2019 (COVID-19) outbreak in January 2020 in China. Med Sci Monit. 2020;26:e923921. https://doi. org/10.12659/MSM.923921

39. Borgonovi F, Andrieu E. Bowling together by bowling alone: Social capital and COVID-19. Soc Sci Med. 2020;265:113501. https:// doi.org/10.1016/j.socscimed.2020.113501

40. Grandner MA, Jackson NJ, Pak VM, Gehrman PR. Sleep disturbance is associated with cardiovascular and metabolic disorders. J Sleep Res. 2012;21(4):427-33. https://doi.org/10.1111/j.1365-2869.2011.00990.x

41. Mullington JM, Haack M, Toth M, Serrador JM, Meier-Ewert HK. Cardiovascular, inflammatory, and metabolic consequences of sleep deprivation. Prog Cardiovasc Dis. 2009;51(4):294-302. https://doi.org/10.1016/j.pcad.2008.10.003 